\title{
Insights into the diversity of choreotrich and oligotrich ciliates (Class: Spirotrichea) based on genealogical analyses of multiple loci
}

${ }^{1}$ Department of Biological Sciences, Smith College, Northampton, MA 01063, USA

2 Department of Marine Sciences, University of Connecticut, Groton, CT 06340, USA

${ }^{3}$ Program in Organismic and Evolutionary Biology, University of Massachusetts-Amherst, Amherst, MA 01003, USA

\author{
Oona L. O. Snoeyenbos-West, ${ }^{1}$ Tovah Salcedo, ${ }^{1}$ George B. McManus ${ }^{2}$ \\ and Laura A. Katz ${ }^{1,3}$
} Author for correspondence: Laura A. Katz. Tel: +1 413585 3825. Fax: + 14135853768.
e-mail: 1katz@smith.edu
To examine relationships among spirotrich ciliates using multi-locus sequence analyses and to provide preliminary insights into molecular diversity within species, we sequenced the small subunit rDNA (SSU rDNA), 5.8S rDNA, $\alpha$-tubulin and the internally transcribed spacer regions (ITS1 and ITS2) of the rDNA genes from seven choreotrich (Class: Spirotrichea) and three oligotrich (Class: Spirotrichea) taxa. Genealogies constructed from SSU rDNA and ITS sequences are concordant and broadly support current classifications based on morphology. The one exception is the freshwater oligotrich Halteria grandinella, which, as has been previously noted, falls outside of the clade containing the other oligotrichs. In contrast, analyses of $\alpha$-tubulin sequences are discordant with traditional taxonomy and rDNA genealogies. These analyses also indicate that considerably more genetic variation exists among choreotrich and oligotrich genera than among stichotrich genera. To explore the level of genetic variation among individuals in temporally isolated populations, we collected additional samples of a subset of planktonic choreotrichs and oligotrichs and characterized polymorphisms in ITS1, ITS2 and 5.8S rDNA. Analyses of these data indicate that, at least for some ciliate lineages, DNA polymorphisms vary temporally, and that genetic heterogeneity underlies some very similar morphological types.

Keywords: ciliophora, spirotrichs, multi-gene genealogies, intraspecific variation

\section{INTRODUCTION}

Recent classification based on analyses of both ciliary patterns and ultrastructural data consistently place three groups, the oligotrichs, stichotrichs and choreotrichs, within the class Spirotrichea, but relationships among the three lineages vary (Corliss, 1974; de

This paper is an elaboration of a presentation to the Society for General Microbiology Special Symposium 'Genomics: beyond the sequence', Heriot-Watt University, Edinburgh, UK, 26-27 March 2001.

Published online ahead of print on 14 June 2002 as DOI 10.1099/ ijs.0.02114-0.

Additional images showing the morphology of the ciliates are available as supplementary data in IJSEM Online (http://ijs.sgmjournals.org).

The GenBank/EMBL/DDBJ accession numbers for the SSU rDNA and $\alpha$-tubulin gene sequences determined in this paper are given in Table 3 .

Abbreviations: ITS1 and ITS2, internally transcribed spacer regions of rRNA genes; SSU, small subunit.
Puytorac et al., 1994; Lynn \& Corliss, 1991; Small \& Lynn, 1985). In Corliss' revision of the class based on infraciliature (Corliss, 1974), the oligotrichs and choreotrichs are united as a single order Oligotrichida, and placed within the spirotrichs along with the order Hypotrichida, which contain both the hypotrichs (e.g. Euplotes) and stichotrichs (e.g. Oxytricha). Similarly, more recent analyses based on morphology unite choreotrichs, oligotrichs and stichotrichs within a single class, although these schemes vary in their treatment of the hypotrichs (de Puytorac et al., 1994; Lynn \& Corliss, 1991; Small \& Lynn, 1985). Particularly relevant to our analyses, the genus Halteria has alternately been considered an oligotrich (e.g. Lynn \& Corliss, 1991; Small \& Lynn, 1985) or as an independent lineage from the oligotrichs and stichotrichs (Petz \& Foissner, 1992).

Previous analyses of molecular data are consistent with morphological analyses in that they support the 
Table 1. Ciliates sampled for this study

\begin{tabular}{|c|c|c|c|c|c|}
\hline Genus/species & Date & Population & Classification & History & No. of cells \\
\hline Eutintinnus pectinis & $23 / 6 / 99$ & Epec99 & C: Tintinnina: Tintinnidae & Grown in culture for $\sim 5$ days & 84 \\
\hline Favella ehrenbergii & $23 / 6 / 99$ & Fehr99 & C: Tintinnina: Ptychocylididae & Field sample & 85 \\
\hline Favella ehrenbergii & $21 / 7 / 00$ & Fehr00 & C: Tintinnina: Ptychocylididae & Grown in culture for $\sim 1$ month & 50 \\
\hline Laboea strobila & $27 / 6 / 00$ & Lstr00 & O: Strombidiidae & Field sample & 61 \\
\hline Metacylis angulata & $6 / 7 / 00$ & Meta 00 & C: Tintinnina: Metacylididae & Grown in culture for $\sim 7$ days & 75 \\
\hline Strobilidium sp. & $3 / 7 / 00$ & Strob00 & C: Strobilidiina: Strobilidiidae & Grown in culture for $\sim 7$ days & $40-50$ \\
\hline Strombidinopsis sp. & $6 / 99$ & Sopsis 99 & C: Strombidinopsina: Strombidinopsidae & Grown in culture for $\sim 1$ year & 200 \\
\hline Strombidinopsis sp. & $7 / 7 / 00$ & Sopsis $00 \mathrm{~A}$ & C: Strombidinopsina: Strombidinopsidae & Field sample & $40-50$ \\
\hline Strombidinopsis sp. & $24 / 7 / 00$ & Sopsis00B & C: Strombidinopsina: Strombidinopsidae & Field sample & $40-50$ \\
\hline Strombidium $\mathrm{sp}$ & $19 / 6 / 00$ & Strom 00 & O: Strombidiidae & Field sample & 41 \\
\hline Tintinnopsis sp. & $14 / 6 / 00$ & Tintsp00C & C: Tintinnina: Codonellidae & Grown in culture for $\sim 7$ days & 40 \\
\hline Tintinnopsis sp. & $7 / 3 / 00$ & Tintsp00A & C: Tintinnina: Codonellidae & Grown in culture for $\sim 7$ days & 75 \\
\hline Tintinnopsis sp. & $25 / 9 / 00$ & Tintsp00B & C: Tintinnina: Codonellidae & Grown in culture & $50-60$ \\
\hline Tintinnopsis tubulosoides & $6 / 99$ & Ttub99 & C: Tintinnina: Codonellidae & Grown in culture for $\sim 7$ days & 39 \\
\hline
\end{tabular}

inclusion of hypotrichs, oligotrichs and stichotrichs within the Spirotrichea. Analyses of small-subunit (SSU) rDNA unite the multiple samples from stichotrichs, hypotrichs and oligotrichs, and place the genus Halteria within, or at least sister to, the stichotrichs (e.g. Shin et al., 2000; Tourancheau et al., 1998). Similarly, data from large-subunit rDNA indicate that oligotrichs and stichotrichs fall within the spirotrich class (Tourancheau et al., 1992).

Although current schemes unite stichotrichs and oligotrichs in the class Spirotrichea, relationships between these two groups and the choreotrichs are ambiguous. In order to explore these relationships further and to evaluate the correspondence between morphologybased taxonomy and gene genealogies, we have analysed sequences for the SSU rDNA, 5.8S rDNA and $\alpha$-tubulin genes as well as two internally transcribed spacer regions (ITS1 and ITS2) from three taxa in the Oligotrichida (Laboea strobila, Halteria grandinella and Strombidium sp.) and seven taxa in the Choreotrichida (Strombidinopsis sp., Eutintinnus pectinis, Tintinnopsis tubulosoides, Tintinnopsis sp., Favella ehrenbergii, Metacylis angulata and Strobilidium sp.; Table 1). In this paper, we examine the branching patterns both within oligotrichs and choreotrichs and among oligotrichs, choreotrichs and stichotrichs, based on genealogical analyses of DNA polymorphisms at multiple loci.

In a pilot study to explore the phylogeography of spirotrichs, we have also characterized the degree of genetic diversity in the 5.8S rDNA gene and in the ITS1 and ITS2 regions within and between populations collected at different time intervals from the same site. Currently, there are two opposing views on ciliate biogeography, but few molecular data exist to test these hypotheses. The first maintains that "in the case of microorganisms "everything is everywhere' and that their global species diversity is relatively limited" (Fenchel et al., 1997). For example, Fenchel et al. (1997) found that approximately $8 \%$ of all described, free-living ciliates were present in core samples repre- senting less than $50 \mathrm{~cm}^{2}$ total of sediment from a small lake and a shallow marine bay. In contrast, following a study of the rate of description of new species and the diversity of species in tropical, temperate and polar soils, Foissner (1997, 1998, 1999) posits that fewer than half of the existing species of ciliates have been described and that considerable endemism exists in ciliate populations.

Our data represent an initial step in determining the degree of molecular diversity within ciliate species and only a few such studies have been done on natural populations. For example, analysis of intraspecific variation in the parasitic ciliate Cryptocaryon irritans using the ITS1 region revealed high divergence $(2 \cdot 9$ $3.5 \%$ ) in morphologically similar isolates from multiple locations in Australia and Europe (Diggles \& Adlard, 1997). Similarly, a study of genetic diversity in freshwater populations of Euplotes aediculatus of different geographical origins, using RAPD fingerprinting, indicates the existence of a large amount of genetic variation (Kusch et al., 2000). Considerable genetic diversity and cryptic species have also been found within the foraminifera (de Vargas et al., 1999, 2001; Holzmann et al., 1996), another clade of protists. The extent to which natural ciliate populations vary at the genetic level has yet to be fully explored and warrants more extensive study.

\section{METHODS}

Sample collection. Two different sampling strategies were used for the genealogical and phylogeographic portions of this study. We first surveyed multiple clones of all molecular markers from single populations of the oligotrichs L. strobila, H. grandinella and Strombidium sp. and the choreotrichs $F$. ehrenbergii, $E$. pectinis, $M$. angulata, Strobilidium sp., Strombidinopsis sp., Tintinnopsis tubulosoides and Tintinnopsis sp. (Table 1). Second, to describe variation in populations over time, additional samples of the ITS1, ITS2 and 5.8S sequences were obtained from populations of Strombidinopsis sp., F. ehrenbergii and Tintinnopsis sp. All ciliates, except for the freshwater ciliate $H$. grandinella, were isolated from Long Island Sound (University of Connecticut dock, Groton, CT, USA) at 
Table 2. Primers used to generate overlapping SSU and ITS sequences

All primers are shown in the $5^{\prime} \rightarrow 3^{\prime}$ orientation.

\begin{tabular}{|ll|}
\hline Gene & \multicolumn{1}{c|}{ Primer sequence } \\
\hline \multirow{2}{*}{ SSU rDNA } & SSUint + 1 : YGGAGARDSRGCYTGAKARAYGGC \\
& SSUint-1 : GACCTGKTATTGCCTYAMRCTTCC \\
& SSUint-2: TTYYCCGTGTTGARTCARATTRAG \\
ITS1-5.8S rDNA-ITS2 & SSU end + : AAGGTWTCCGTAGGTGAACCTG \\
& LSU start - : TAKTRAYATGCTTAAGTYCAGCG \\
\hline
\end{tabular}

dates indicated in Table 1. Whenever a given species was abundant, cells were picked directly from either whole water or $64 \mu \mathrm{m}$ mesh plankton net concentrates. In other cases ciliates were cultured in filtered, autoclaved seawater supplemented with cultured microalgae, Prorocentrum minimum, Rhodomonas sp. and Isochrysis galbana, as food. One isolate of Strombidinopsis sp. (Sopsis99) was in culture for approximately one year prior to DNA analysis. To provide a comparison for levels of variation in clonal lines of ciliates, samples of $H$. grandinella were collected from the pond at the Lyman Plant House (Smith College) and used to generate clonal lines by passing individual cells through a minimum of three washes in clean culture medium.

Species identification. All tintinnids were identified to lowest possible taxon using light microscopic examination of lorica morphology, as is traditional in this group (e.g. Laval-Peuto \& Brownlee, 1986). Characters used included shape and measurements of the oral diameter and maximal width and length of loricas. We compared our samples with published descriptions from a number of sources, including Bakker \& Phaff, (1976), Gold \& Morales (1975), Hedin (1974), Lee et al. (1985) and Marshall (1969). For hyaline taxa we are confident that our diagnoses are in keeping with current literature, but for agglutinated genera (i.e. those that adhere scavenged mineral or organic particles to their loricas) such as Tintinnopsis, lorica shape is less constant, and identification to species level is more difficult. For hyaline species, $F$. ehrenbergii, $M$. angulata and $E$. pectinis, lorica morphology is considered to be a reliable character, although divergent lorica shapes have been observed within species in culture (e.g. Laval-Peuto, 1977, 1981). For the agglutinated T. tubulosoides, we felt that identification to species was possible based on published descriptions and also on personal communications with colleagues who had observed this species from other coastal sites in the north-eastern US. For other isolates in this genus, we were not confident that designation of a species name was appropriate, given the variation in lorica characters within the samples we collected. We thus designate these isolates as Tintinnopsis spp.

Except for much older literature (e.g. Kahl, 1930-1935), descriptions of oligotrichs and non-tintinnid choreotrichs have been based on observations of infraciliature obtained from electron microscopy or light microscopy of protargolstained specimens (e.g. Montagnes \& Lynn, 1991). In some cases, however, good identifications to species can be made based on unique morphological characters, behaviours, etc., without resort to these techniques (e.g. Carey \& Maeda, 1985; Maeda, 1986). For example, the oligotrich Laboea strobila is the only described species in its genus (Corliss, 1979) and has both a unique spiral winding of the girdle around the posterior of the cell and the habit of retaining chloroplasts from ingested algae (McManus \& Fuhrman, 1986). We observed these characters with the light microscope to identify this species. Strombidium sp., Strombidinopsis sp. and Strobilidium sp. were identified to genus based on the presence and length of body cilia, whether or not the oral membranelles formed a closed circle, general body shape and swimming behaviour. Samples of all of the isolates were preserved in Bouin's fixative, the preferred fixative for protargol staining (Montagnes \& Lynn, 1987), so future precise comparisons with published descriptions will be possible.

DNA extraction, amplification, cloning and sequencing. Individual cells were transferred to lysis buffer solution according to standard protocols (Ausubel et al., 1993), and PCR (Saiki et al., 1988) was performed as described in Riley \& Katz (2001). Primers for SSU rDNA genes are from Medlin et al. (1998) with three additional primers used to generate overlapping sequences from each clone (Table 2). Primers and strategies for amplifying and cloning the $\alpha$ tubulin gene are described in Riley \& Katz (2001). We also designed primers that target $477 \mathrm{bp}$ of rDNA encompassing ITS1, ITS2 and 5.8S rDNA (Table 2).

PCR products were cleaned using the Qiagen Qiaquick PCR Purification System, and cloned using either the Gibco-BRL pAMP1 System or the Invitrogen TOPO TA Cloning Kit. Plasmid DNA was purified using the Qiagen MiniPrep Kit. Direct sequencing of PCR products, or cloned plasmid DNA, was accomplished in both directions using genespecific primers and the BigDye terminator kit (Perkin Elmer). Sequences were run on an ABI 377 or ABI 310 automated sequencer.

Genealogical analysis. We generated contigs by assembling and editing sequences using SeqMan (DNAStar). Alignments combined our data with sequences available on GenBank (see Figs 1-3) using the CLUSTAL w algorithm (Thompson et al., 1994) as implemented in MEGALIGN (DNAStar) for $\alpha$-tubulin and the ITS regions, and the dedicated comparative sequence editor (De Rijk \& De Wachter, 1993) for SSU rDNA. The $\alpha$-tubulin alignment was unambiguous and the rDNA alignments were adjusted by eye. For SSU rDNA and the ITS datasets, these alignments yield 1782 and 305 characters (331 and 209 of which are parsimony-informative), respectively, after excluding ambiguously aligned regions. For $\alpha$-tubulin, the nucleotide alignment included 1095 sites (368 parsimonyinformative sites) and the amino acid alignment included 365 sites (36 parsimony-informative sites; all alignments are available by request from the authors). 
Genealogical analyses of SSU rDNA, ITS and $\alpha$-tubulin nucleotide data were performed using the maximumlikelihood (ML), maximum-parsimony (MP) and LogDet (LD) heuristic searches implemented in PAUP* version 4.0b (Swofford, 1999). MODELTEST version 3.04 (Posada \& Crandall, 1998) was used to determine an appropriate model and to estimate parameters for maximum-likelihood analyses. For MP, a strict consensus tree was generated from a heuristic search with 10 random addition sequences. Heuristic searches were also done excluding invariant sites using LD distances to account for compositional biases (Lockhart et al., 1996; Swofford et al., 1996). For the $\alpha$-tubulin data, we also analysed the amino acid alignment with the neighbourjoining $(\mathrm{NJ})$ algorithm with mean character distances and MP with 10 random addition sequences in heuristic searches with PAUP* 4.0b (Swofford, 1999). Bootstrap values were calculated using 100 replicates under all models.

\section{RESULTS}

\section{Genealogies}

SSU rDNA. Between three and six SSU rDNA clones per taxon were sequenced and the mean percentage divergence within taxa ranged from 0.069 to $0.410 \%$ (Table 3). For Strobilidium sp. and Strombidium sp., a consensus sequence was made from overlapping clones in order to obtain a full-length sequence, because characterization of the entire $1.6 \mathrm{~kb}$ region could only be accomplished by amplifying two overlapping products of $\sim 1.2 \mathrm{~kb}$ each.

Genealogical analyses of the SSU rDNA sequences used multiple algorithms and evolutionary models to assess the stability of our topologies. In these analyses, the sequences from the choreotrichs ( $T$. tubulosoides, M. angulata, Strobilidium sp., Strombidinopsis sp., $F$. ehrenbergii and $E$. pectinis) form a monophyletic group with bootstrap support of 96,72 and $83 \%$ for LD, MP and ML models, respectively (Fig. 1). Moreover, the Tintinnina (T. tubulosoides, M. angu- lata, $F$. ehrenbergii and $E$. pectinis) are monophyletic, although with weaker bootstrap support. In contrast, the oligotrichs are polyphyletic, with the H. grandinella sequence falling within the stichotrichs. The monophyly of $H$. grandinella plus the stichotrichs is strongly supported with bootstrap values of 100, 100 and $96 \%$ for LD, MP and ML, respectively. With the exception of $H$. grandinella sequences, the oligotrich sequences (L. strobila, Strombidium sp. and the previously published Strombidium purpureum sequence, GenBank no. U97112) are monophyletic, with bootstrap support of 93, 71 and $72 \%$ for LD, MP and ML.

ITS. Analyses of the aligned ITS1, 5.8S rDNA and ITS2 data are concordant with the SSU rDNA genealogies (Fig. 2). For analyses of these data, we included a single sequence, either the most common haplotype or a randomly chosen clone, from each of 13 clades as determined from our phylogeographic study. In these analyses, the choreotrich sequences are monophyletic (bootstrap support of 97,82 and $90 \%$ for LD, $\mathrm{MP}$ and $\mathrm{ML}$, respectively) as are the Tintinnina (bootstrap support of 100, 97 and $92 \%$ for LD, MP and $\mathrm{ML}$, respectively). The oligotrichs are again split into two groups. As in the SSU rDNA genealogy, the $H$. grandinella sequence falls sister to a subset of Oxytricha sp. sequences, albeit with low bootstrap values of 51,77 and $52 \%$ for LD, MP and ML, respectively. The remaining oligotrichs are monophyletic, with strong bootstrap support of 98, 100 and $100 \%$ for LD, MP and ML, respectively.

$\boldsymbol{\alpha}$-Tubulin. We sequenced four clones each from $M$. angulata, F. ehrenbergii, L. strobila and Strombidium sp., three clones from Tintinnopsis sp., five clones each from E. pectinis and Strobilidium sp., and seven from Strombidinopsis sp. In contrast to the ITS and SSU data, there was considerably more intraspecific variation in some lineages (Table 3 ) with the number of variable sites among the 1095 characterized for each

Table 3. Within-species variation for SSU and $\alpha$-tubulin

Divergence values for taxa that have $\alpha$-tubulin paralogues are indicated in bold; Div, divergence.

\begin{tabular}{|c|c|c|c|c|c|c|}
\hline \multirow[t]{2}{*}{ Taxon } & \multicolumn{3}{|c|}{ SSU rDNA } & \multicolumn{3}{|c|}{$\alpha$-Tubulin } \\
\hline & $\begin{array}{l}\text { No. of } \\
\text { clones }\end{array}$ & $\begin{array}{l}\text { Div } \\
(\%)\end{array}$ & GenBank no. & $\begin{array}{l}\text { No. of } \\
\text { clones }\end{array}$ & $\begin{array}{l}\text { Div } \\
(\%)\end{array}$ & GenBank no. \\
\hline Strombidinopsis sp. & 4 & $0 \cdot 165$ & AF399132-AF399135 & 7 & 3.86 & AF399136-AF399142 \\
\hline Favella ehrenbergii & 6 & $0 \cdot 166$ & AF399159-AF399164 & 4 & $0 \cdot 414$ & AF399165-AF399168 \\
\hline Eutintinnus pectinis & 3 & $0 \cdot 410$ & AF399169-AF399171 & 5 & $0 \cdot 474$ & AF399172-AF399175 \\
\hline Tintinnopsis tubulosoides & 5 & $0 \cdot 123$ & AF399108-AF399111 & 3 & $0 \cdot 363$ & AF399112-AF399114 \\
\hline Metacylis angulata & 4 & $0 \cdot 200$ & AF399143-AF399146 & 4 & $0 \cdot 122$ & AF399147-AF399150 \\
\hline Strobilidium sp. & $1 *$ & $\mathrm{~N} / \mathrm{A}$ & AF399122-AF399127 & 5 & $9 \cdot 21$ & AF399128-AF399131 \\
\hline Strombidium sp. & $1 *$ & $\mathrm{~N} / \mathrm{A}$ & AF399115-AF399117 & 4 & $3 \cdot 77$ & AF399118-AF399121 \\
\hline Laboea strobila & 4 & $0 \cdot 069$ & AF399151-AF399154 & 4 & $2 \cdot 62$ & AF399155-AF399158 \\
\hline
\end{tabular}

* Consensus sequences based on overlapping regions (see Results: Genealogies). 


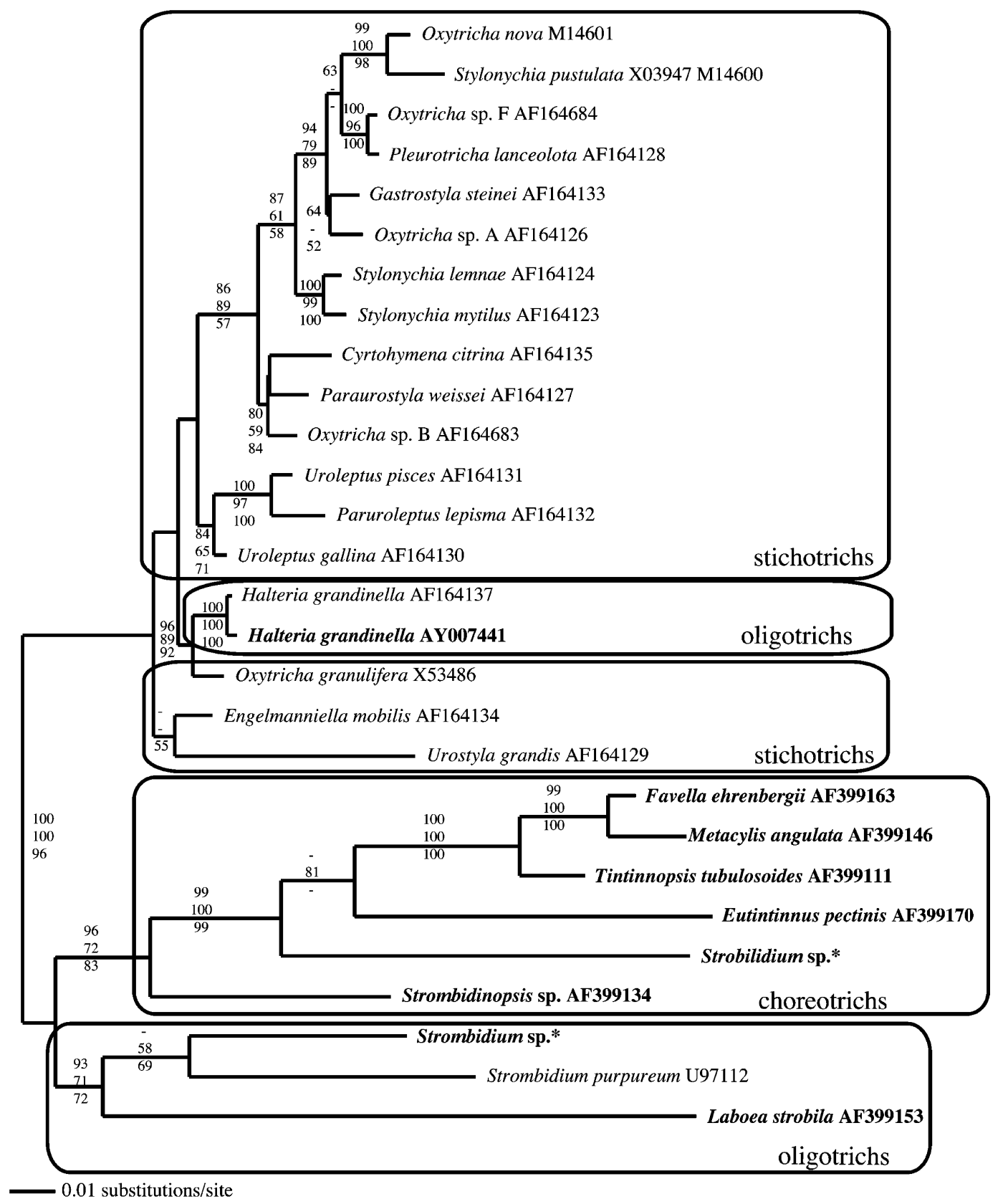

Fig. 1. Genealogy of spirotrich SSU rDNA based on maximum-likelihood analysis. For ML analyses, the hierarchical likelihood ratio test implemented in MODELTEST (Posada \& Crandall, 1998) selected the Tamura \& Nei (1993) model with among site variation of 0.5878 and a gamma distribution of 0.6239 . Numbers on branches represent bootstrap values for LogDet (LD), maximum-parsimony (MP), and maximum-likelihood (ML), respectively; bootstrap values less than 50 not shown. GenBank accession numbers follow taxonomic names; our taxa are shown in bold; asterisk indicates consensus sequence used in analyses (see Methods). Further details can be found in Methods.

clone ranging from as few as two in the $M$. angulata to as many as 149 in the Strobilidium sp. We define paralogues as sequences that show greater than $2 \%$ sequence divergence, based on previous studies in our laboratory that indicate that allelic variation, macronuclear variation and experimental error are less than $\sim 1 \%$ (Riley \& Katz, 2001; Israel et al., 2002). One of the apparent paralogues in Strobilidium sp. (repre- sented by two of our clones, GenBank nos AF299128 and AF399130) has a single base-pair deletion that could either indicate a pseudogene or a macronuclear variant; for our genealogical analyses, we treated this character as a gap.

In genealogies generated for both nucleotide and amino acid alignments of the $\alpha$-tubulin data, 


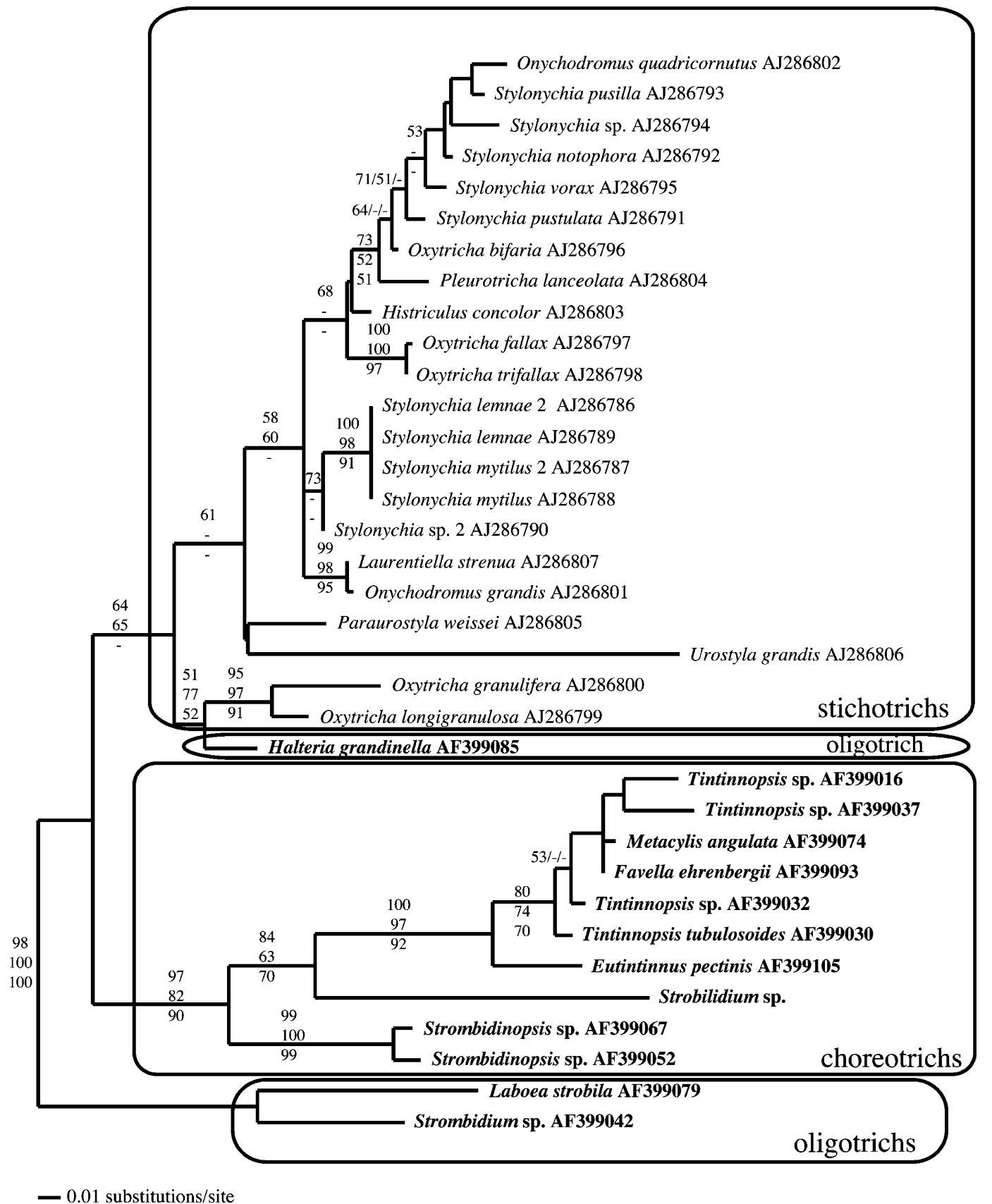

Fig. 2. Genealogy of spirotrich ITS1-5.8S rDNA-ITS2 based on maximum-likelihood analysis. For the ML analysis, hierarchical ratio tests indicated the Tamura \& Nei (1993) model with among-site variation of 0.3009 and a gamma distribution of 0.5904. Other notes as in Fig. 1.

topologies are discordant with those generated from the SSU rDNA and ITS datasets, and in all cases, apparent paralogous copies of $\alpha$-tubulin are sister to one another or cluster within a genus (Fig. 3). In analyses of nucleotide data, the choreotrich $\alpha$-tubulin sequences are polyphyletic and form four groups: (1) F. ehrenbergii, T. tubulosoides and M. angulata; (2) E. pectinis; (3) Strombidinopsis sp. and (4) Strobilidium sp. (Fig. 3). Moreover, in these analyses, the H. gran- dinella sequences fall as sister to the Tintinnina sequences, with bootstrap support of 79,97 and $95 \%$ for LD, MP and ML, respectively. Finally, the oligotrich sequences are also polyphyletic, with the L. strobila and Strombidium sp. paralogues clustering separately. Analyses of amino acid sequences using MP are unresolved and with the NJ algorithm, three monophyletic groups emerge - (1) stichotrichs plus $H$. grandinella, (2) oligotrichs and (3) Tintinnina- 


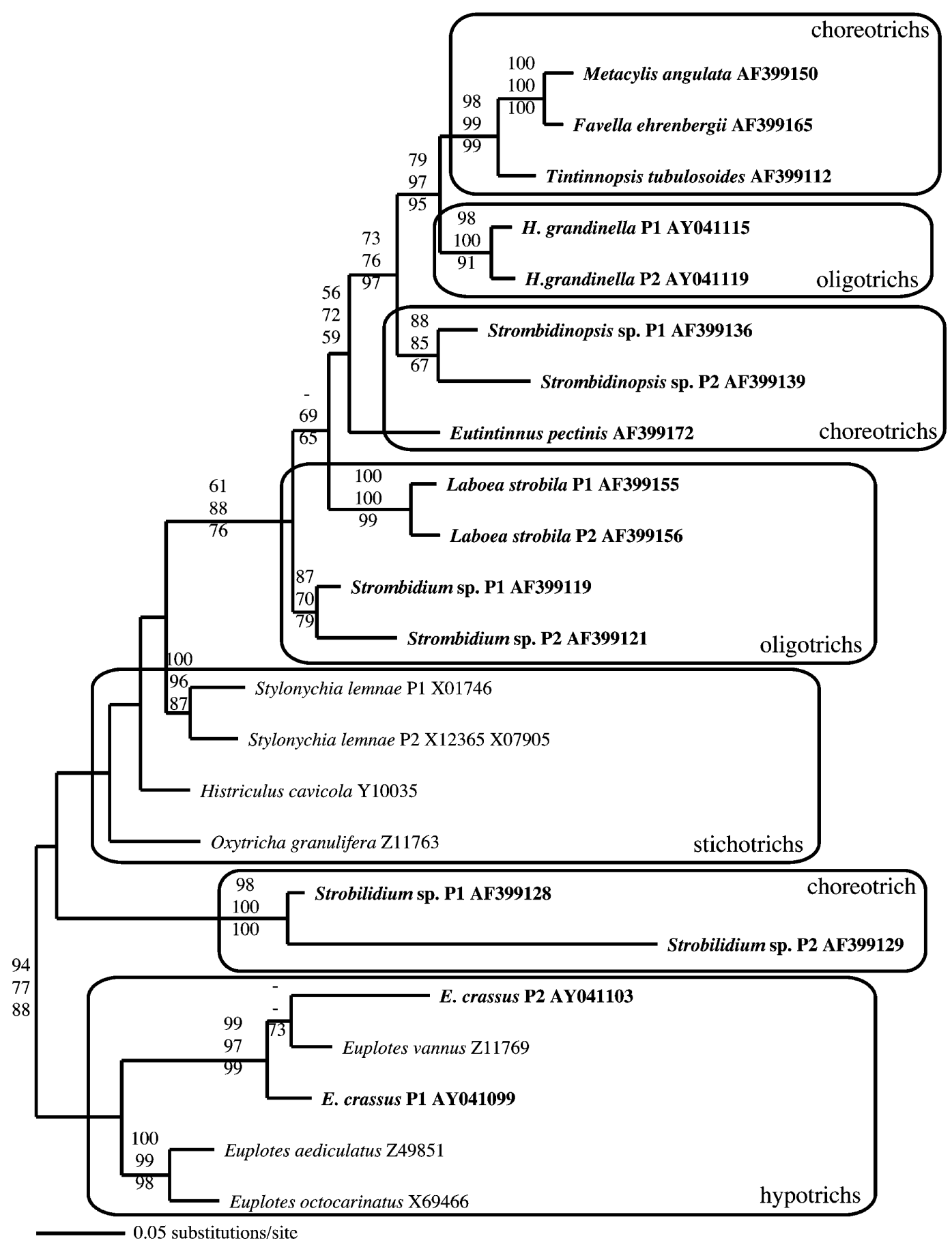

Fig. 3. Genealogy of spirotrich $\alpha$-tubulin nucleotide sequences based on maximum-likelihood analysis. For the ML analysis, hierarchical ratio tests indicated the TrN model (Tamura \& Nei, 1993) with among site variation of 0.4151 and a gamma distribution parameter of 1.0353. P1 and P2 designate paralogous copies within taxa. Other notes as in Fig. 1.

although bootstrap support in these analyses is low $(<50-68 \%$ - data not shown).

\section{Temporal patterns of intraspecific variation}

To assess the genetic heterogeneity within and between populations, we characterized DNA polymorphisms at the ITS locus in 95 clones from 14 populations representing nine genera (see Table 1; GenBank nos AF399013-AF399107). For some samples (Epec99, Fehr99, Fehr00, Lstr00, Meta00 and Ttub), species designations based on morphologic identification are clear, but for others (Strob00, Sopsis99, Sopsis00A, Sopsis00B, Strom00, TintspA00, TintspB00 and TintspC00), identifications are only to genus level (Table 1). To explore the levels of variation within and 


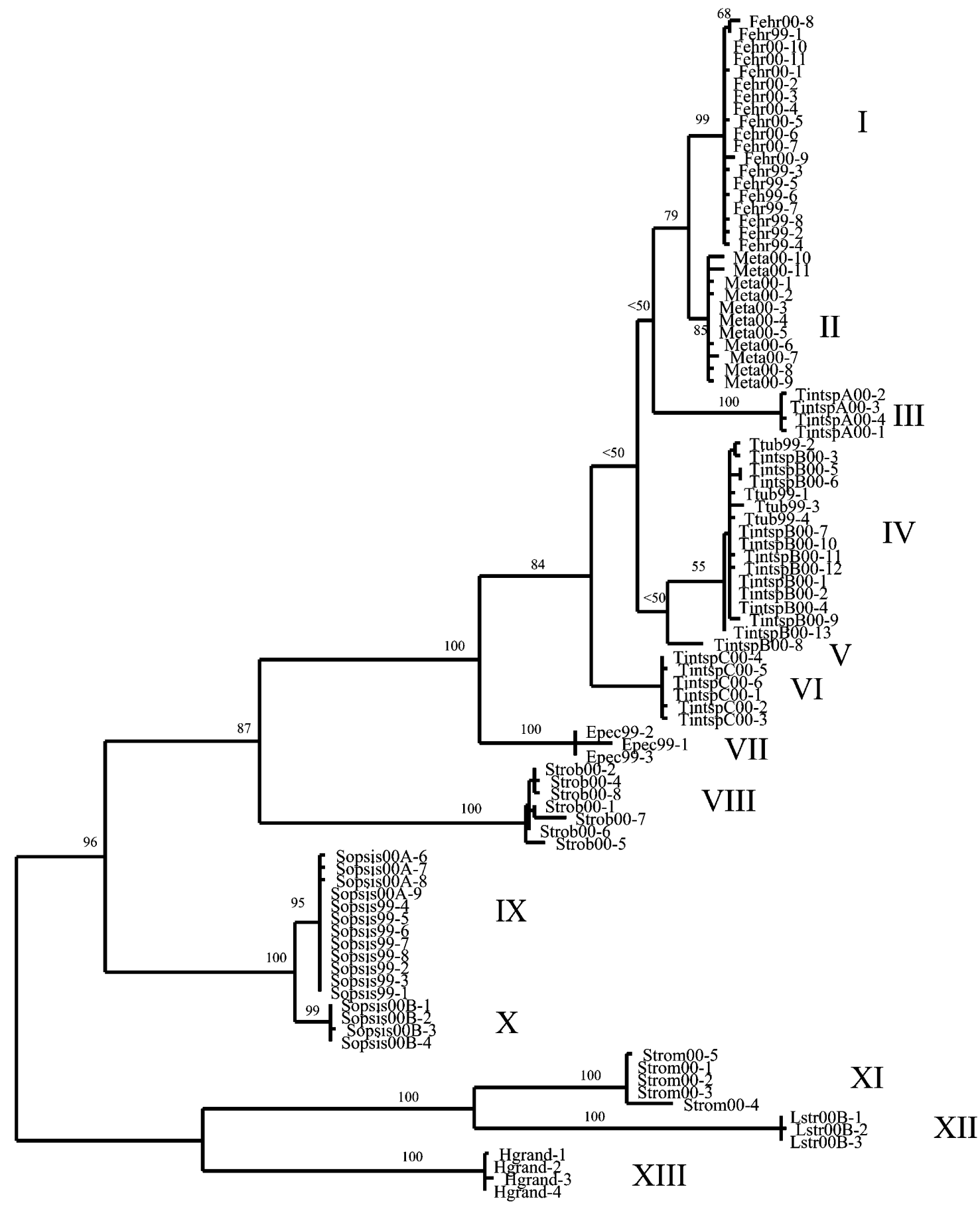

5 changes

Fig. 4. Intraspecific analysis of spirotrich ITS data. Topology is one of $>3000$ most parsimonious trees generated by PAUP* with gaps treated as a fifth character state, and is shown to emphasize branch lengths. Numbers on branches represent bootstrap values from 100 replicates.

between populations, we constructed a single genealogy using MP with gaps treated as a fifth state (for a full genealogical exploration of these data, see above). Our genealogical analyses of ITS1, 5.8S rDNA and ITS2 regions from multiple clones from popu- lations of nine genera reveal 13 well-supported monophyletic groups, although relationships among these 13 clades, particularly within the Tintinnina, are not well supported (Fig. 4). As expected, intrapopulation divergence values are lower than interpopulation 
Table 4. Uncorrected mean percentage nucleotide sequence divergence among sequences within groups

\begin{tabular}{|clc|}
\hline Marker & \multicolumn{1}{c|}{ Taxon } & $\begin{array}{c}\text { Mean } \\
\text { divergence (\%) }\end{array}$ \\
\hline \multirow{2}{*}{ SSU rDNA } & Choreotrichida & $7 \cdot 48$ \\
& Oligotrichida & $8 \cdot 17$ \\
& Stichotrichida & $2 \cdot 97$ \\
ITS1-5.8S & Choreotrichida & $7 \cdot 37$ \\
rDNA-ITS2 & Oligotrichida & $9 \cdot 26$ \\
& Stichotrichida & $6 \cdot 74$ \\
\multirow{2}{*}{-Tubulin } & Choreotrichida & $13 \cdot 03$ \\
& Oligotrichida & $9 \cdot 04$ \\
& Stichotrichida & $7 \cdot 83$ \\
\hline
\end{tabular}

Table 5. Intraclade distances calculated using uncorrected estimates

\begin{tabular}{|llc|}
\hline Clade & \multicolumn{1}{c|}{ Population } & Divergence \\
\hline I & Fehr99 and Fehr00 & $0 \cdot 003$ \\
II & Meta00 & $0 \cdot 005$ \\
III & TintspA00 & $0 \cdot 003$ \\
IV & Ttub99 and TntspB00 & $0 \cdot 003$ \\
V & TintspB00 & $0 \cdot 003$ \\
VI & TintspC00 & $0 \cdot 002$ \\
VII & Epec99 & $0 \cdot 009$ \\
VIII & Strob00 & $0 \cdot 005$ \\
IX & Sopsis99 and Sopsis00A & $0 \cdot 000$ \\
X & Sopsis00B & $0 \cdot 002$ \\
XI & Strom00 & $0 \cdot 006$ \\
XII & Lstr00 & $0 \cdot 001$ \\
XIII & Hgrand & $0 \cdot 003$ \\
\hline
\end{tabular}

* Clonal line.

comparisons (Tables 5 and 6), with the one exception of the TintspB00 sample which contained sequences in clades IV and V. Clades II, VIII, XI and VII, representing clones sampled from $M$. angulata, Strobilidium sp., Strombidium sp. and E. pectinis, show very little variation $-0.3-0.9 \%$ (Fig. 4 , Table 5). These levels are comparable to the level of variation within a clonal line of $H$. grandinella $(0 \cdot 3 \%)$.

Variation between populations. Analyses of the ITS dataset show contrasting patterns of variation in different taxa (Fig. 4, Table 5). For example, F. ehrenbergii (Fehr99/Fehr00; Clade I) and Strombidinopsis sp. (Sopsis99/Sopsis00A; Clade IX) sampled in two different summers contain identical ITS haplotypes. In contrast, there was considerable $(>2 \%)$ variation between samples of Strombidinopsis sp. collected just 17 days apart: Sopsis00A (Clade IX) and Sopsis00B (Clade X), and Tintinnopsis sp. sampled in June, July and September of the same year (Tintsp00C, Tintsp00A and Tintsp00B, respectively; see Table 6). Moreover, the clades from the genus Tintinnopsis (Clades III, IV, V and VI) are not monophyletic with respect to $M$. angulata (Clade II) and E. pectinis (Clade VII; Fig. 4).

Variation within and between morphological entities. Two striking patterns emerge from comparisons of genetic variation within morphologically defined taxa. We find identical sequences in samples of two morphologically distinct Tintinnopsis populations, TintspB00 and Ttub99 and the mean divergence between these populations is $0.3 \%$ (Clade IV, Fig. 4; Table 6). In contrast, we found one clone, TintspB00-8 (Clade V), which is $4.5 \%$ divergent from other clones characterized from within the same TintspB00 sample (Clade IV; Table 6).

\section{DISCUSSION}

\section{Concordance and discordance between genealogies}

Not surprisingly, the genealogies generated from the linked SSU rDNA and ITS regions yield similar topologies (Figs 1 and 2). For instance, the Tintinnina clustered together with bootstrap values of 99,81 and less than $50 \%$ in the SSU rDNA genealogy, and 100,

Table 6. Intra- and intersample distances for Tintinnopsis sp. and Strombidinopsis sp.

Calculated using uncorrected distances. Values within a clade are shown in bold.

\begin{tabular}{|lcccccc|}
\hline Clade ... & III & IV & V & VI & IX & X \\
\hline Tintinnopsis clades & & & & & & \\
III & $\mathbf{0 . 0 0 3}$ & 0.077 & 0.080 & 0.085 & - & - \\
IV & - & $\mathbf{0 . 0 0 3}$ & 0.045 & 0.074 & - & - \\
V & - & - & - & 0.069 & - & - \\
VI & - & - & - & $\mathbf{0 . 0 0 2}$ & - & - \\
Strombidinopsis clades & & & & & & \\
IX & - & - & - & - & $\mathbf{0 . 0 0}$ & 0.026 \\
X & - & - & - & - & - & $\mathbf{0 . 0 0 2}$ \\
\hline
\end{tabular}


97 and $92 \%$ in the ITS genealogy for LD, MP and ML, respectively. An exception to this concordance is the paraphyly of the Tintinnopsis sp. samples in the ITS analyses (Fig. 2), although bootstrap values for the split between T. tubulosoides and the three Tintinnopsis sp. samples are low in all analyses. In contrast, the $\alpha$ tubulin genealogy (Fig. 3) is not concordant with the SSU rDNA and ITS genealogies, as the choreotrichs, stichotrichs and oligotrichs are polyphyletic.

Our data do not support merging the oligotrichs and choreotrichs into a single unit at the same taxonomic level as the stichotrichs. In fact, comparisons of mean pairwise differences among sequences reveals that there is more variation among the choreotrichs and oligotrichs sampled than within the stichotrichs (Table 4). For the SSU rDNA data, where the pattern is clearest, variation among stichotrichs is on average $2.97 \%$, while the variation among choreotrichs and oligotrichs is 8.17 and $7.48 \%$, respectively (Table 4). The variation within oligotrichs, which have the highest levels at all markers, is confounded by the taxonomic designation of $\mathrm{H}$. grandinella, as sequences from this taxon do not cluster with the other oligotrichs (Figs 1-3). The same trend holds for the ITS and $\alpha$-tubulin data, although there are smaller differences in divergence between clades (Table 4).

\section{Concordance between genealogies and taxonomy}

Our analyses provide the first hypothesis on relationships among stichotrichs, oligotrichs and choreotrichs based on molecular genealogies. We find general concordance between our SSU rDNA and ITS genealogies and morphological taxonomy, but only some concordance with the $\alpha$-tubulin data. Our analyses of rDNA regions unite the oligotrichs and choreotrichs, excluding the $H$. grandinella sequences (Figs 1 and 2). These analyses also provide insights into relationships within choreotrichs, and indicate that some of the hyaline tintinnids (e.g. F. ehrenbergii, $M$. angulata) are more closely related to agglutinated Tintinnopsis species than they are to other hyaline species (e.g. E. pectinis; Figs 1 and 2). In light of this, further study of the suitability of lorica-type as a taxonomic marker is warranted.

Similarly, our analyses indicate the need for additional loci and samples to determine the phylogenetic placement of $H$. grandinella. In all three genealogies, the $H$. grandinella sequences are in a distinct clade from the other oligotrichs, although the sister taxon to this lineage varies depending on the locus analysed (Figs $1-3)$. In the SSU rDNA and ITS genealogies, the $H$. grandinella sequence falls within the stichotrichs, consistent with previous analyses of SSU rDNA (Hoffmann \& Prescott, 1997; Shin et al., 2000). However, previous support for this hypothesis was weak, since earlier molecular studies did not include choreotrichs and other oligotrich sequences. In the $\alpha$-tubulin nucleotide analyses, $H$. grandinella is sister to the Tintinnina sequences, although this topology disagrees with traditional taxonomy in many other respects.

\section{$\alpha$-Tubulin paralogues}

The presence of duplicated copies of $\alpha$-tubulin paralogues may explain the discordance between the genealogical analyses of this locus and both rDNA loci and morphology. Using a cut-off value of $>2 \%$ divergence, we found paralogues in L. strobila, Strombidium sp., Strombidinopsis sp. and Strobilidium sp. The low levels of ITS (Table 5) and SSU rDNA (Table 3) variation within these populations provides further evidence that divergent $\alpha$-tubulin sequences are paralogues, not alleles. Each pair of paralogues clustered either within species or within a genus, and at least one representative of each of the four spirotrich groups had paralogues. A model of $\alpha$-tubulin evolution that combines duplication and gene conversion is consistent with the discordant topology; however, analyses of additional loci are required to distinguish among alternative hypotheses.

\section{Phylogeography of oligotrichs and choreotrichs}

In our preliminary analyses of ITS1 and ITS2, we observed contrasting patterns of intraspecific variation in different populations of taxa isolated from the plankton. For example, populations of the tintinnid F. ehrenbergii sampled in 1999 (Fehr99) and 2000 (Fehr00) were identical with respect to ITS sequence (Fig. 4 and Table 5), even though regular sampling (at least weekly) indicated that this species was absent or at extremely low abundance during the intervening months. Strombidinopsis spp. and Tintinnopsis spp. samples do not show this stable pattern, but rather show considerable variation between populations sampled at different times (Fig. 4 and Table 6). In future work, we hope to identify environmental factors (e.g. dissolved oxygen concentrations, phytoplankton biomass and diversity, and temperature) that may correlate to the population-level differences we see at the genetic level. In addition, the use of morphology alone in defining taxonomic groups may obscure genetic variation among cryptic species and explain the high levels of variation we found in some samples (e.g. TintspB00 in Table 6; clades IV and V in Fig. 4).

\section{Relating morphology to genetics in ciliates}

The research presented here is one of the first studies to analyse molecular data to describe the diversity of oligotrich and choreotrich ciliates. Previous attempts to survey the diversity and biogeography of marine tintinnids have relied on traditional approaches based on morphology alone (e.g. Dolan, 2000; Dolan \& Gallegos, 2001; Perez et al., 2000; Pierce \& Turner, 1993; Thompson et al., 1999). One of the surprising results of our study is the discovery that $T$. tubulosoides 

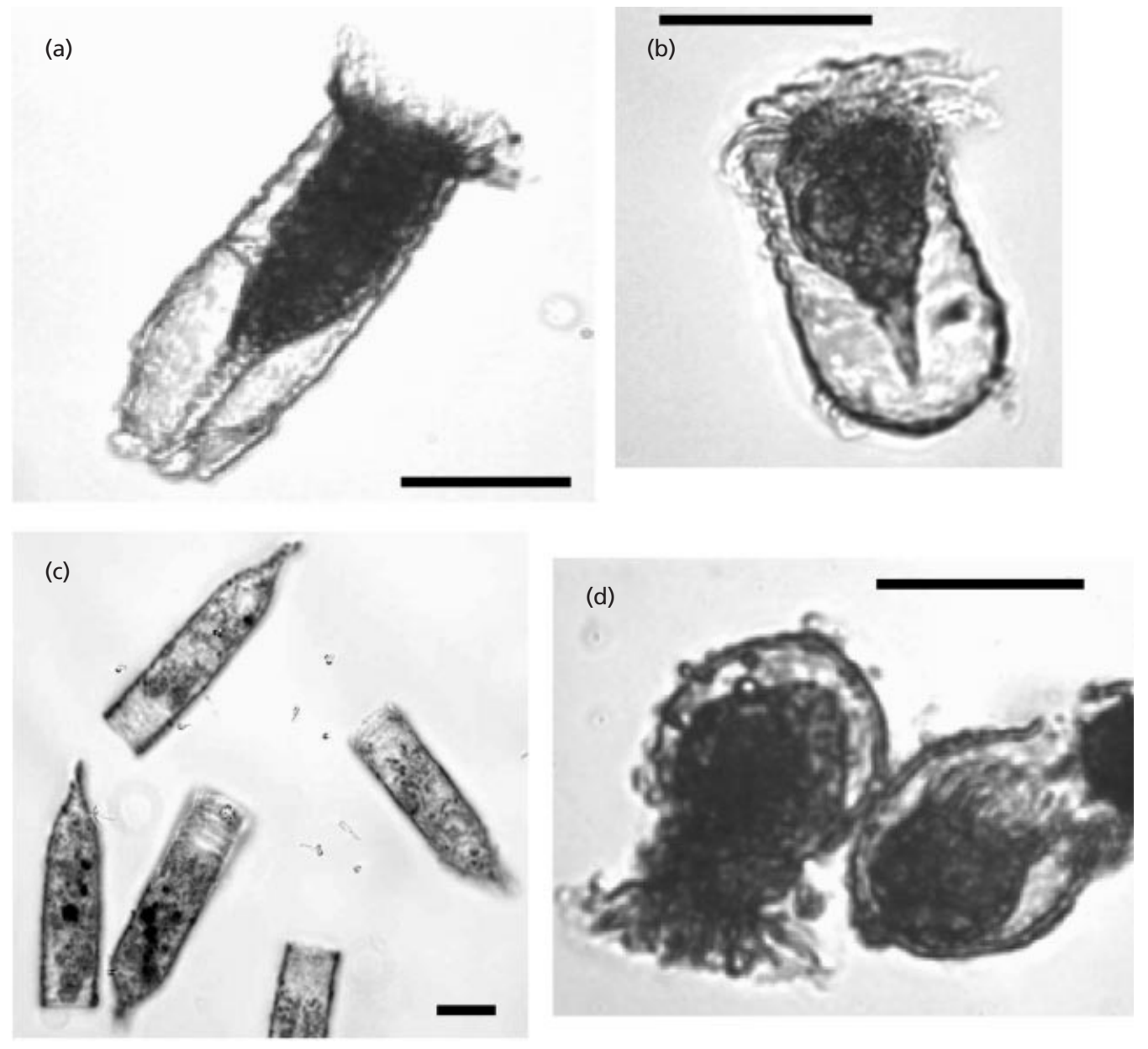

Fig. 5. Light micrographs of representatives of the four populations of tintinnids, illustrating the range of morphological variation: (a) Ttub99, (b) Tintsp00A, (c) Tintsp00B and (d) Tintsp00C. Scale bars, $30 \mu \mathrm{m}$. Based on lorica morphology and dimensions, these four isolates would likely be designated as separate species, or perhaps as only three species, with Ttub99 and Tintsp00A being lumped together [(a) and (b), respectively]. Our sequence data show Ttub99 and Tintsp00B to be identical $[(a)$ and (c), respectively] and distinct from the other two. Additional images showing the morphology of the ciliates is available as supplementary data in IJSEM Online (http://ijs.sgmjournals.org).

and members of the Tintsp00B population, an apparently distinct morphological entity, are genetically identical at the ITS locus [Fig. 5(a, c) \& Table 5]. This confirms concerns that lorica morphology is unreliable for phylogenetic reconstruction (Laval-Peuto \& Brownlee, 1986), and that within the tintinnids, lorica morphology may result from ecotypic variation (e.g. Laval-Peuto, 1977, 1981). Similar concerns on the suitability of hard-part morphology for the classification of other testate protists, such as the foraminifera, have recently been confirmed by use of molecular approaches to look at genetic variation within species (e.g. Darling et al., 2000; de Vargas et al., 2001; Holzmann et al., 1996; Norris \& de Vargas, 2000). Our confirmation that lorica morphology appears to be a poor trait for classifying tintinnids has implications not only for extant taxa, but also for classification schemes based on tintinnid microfossils that rely on hard-part morphology alone, since there is no recourse to molecular data to test such designations. Moreover, these results underscore the need for studies on genetic variability in natural ciliate populations, as our initial molecular surveys suggest that ITS regions will provide adequate polymorphism data to allow us to assess biogeographic variation in ciliates.

\section{ACKNOWLEDGEMENTS}

O.L.O.S.-W. and T.S. share first authorship, having made equal contributions to this paper. Many thanks to Carol Rosetta and Erica Lasek-Nesselquist for their help in collecting ciliates and sequences and to the comments of two anonymous reviewers. This work is supported by an NSF Small Grant in Exploratory Research to LAK (NSF \#0079325), A. F. Blakeslee Funds at Smith College administered through the National Academy of Sciences, a Howard Hughes Medical Institute grant for undergraduate research at Smith College and by Connecticut Sea Grant to G.B.M. 


\section{REFERENCES}

Ausubel, F. M., Brent, R., Kingston, R. E., Moore, D. D., Seidman, J. G., Smith, J. A. \& Struhl, K. (1993). Current Protocols in Molecular Biology. New York: Wiley-Liss.

Bakker, C. \& Phaff, W. J. (1976). Tintinnida from coastal waters of the S. W.-Netherlands I. The genus Tintinnopsis Stein. Hydrobiologia 50, 101-111.

Carey, P. G. \& Maeda, M. (1985). Horizontal distribution of psammophilic ciliates in fine sediments of the Chichester Harbor area. J Nat Hist 19, 555-574.

Corliss, J. O. (1974). The changing world of ciliate systematics: historical analysis of past efforts and a newly proposed phylogenetic scheme of classification for the protistan phylum Ciliophora. Syst Zool 23, 91-138.

Corliss, J. O. (1979). The Ciliated Protozoa:Characterization, Classification and Guide to the Literature. Oxford: Pergamon Press.

Darling, K. F., Wade, C. M., Stewart, I. A., Kroon, D., Dingle, R. \& Brown, A. J. L. (2000). Molecular evidence for genetic mixing of Arctic and Antarctic subpolar populations of planktonic foraminifers. Nature 405, 43-47.

de Puytorac, P., Grain, J. \& Legendre, P. (1994). An attempt at reconstructing a phylogenetic tree of the Ciliophora using parsimony methods. Eur J Protistol 30, 1-17.

De Rijk, P. \& De Wachter, R. (1993). DCSE v2.54, an interactive tool for sequence alignment and secondary structure research. Comput Applic Biosci 9, 735-740.

de Vargas, C., Norris, R., Zaninetti, L., Gibb, S. W. \& Pawlowski, J. (1999). Molecular evidence of cryptic speciation in planktonic foraminifers and their relation to oceanic provinces. Proc Natl Acad Sci $U S A$ 96, 2864-2868.

de Vargas, C., Renaud, S., Hilbrecht, H. \& Pawlowski, J. (2001). Pleistocene adaptive radiation in Globorotalia truncatulinoides: genetic, morphologic, and environmental evidence. Paleobiology 27, 104-125.

Diggles, B. K. \& Adlard, R. D. (1997). Intraspecific variation in Cryptocaryon irritans. J Eukaryot Microbiol 44, 25-32.

Dolan, J. R. (2000). Tintinnid ciliate diversity in the Mediterranean Sea: longitudinal patterns related to water column structure in late spring-early summer. Aquat Microb Ecol 22, 69-78.

Dolan, J. R. \& Gallegos, C. L. (2001). Estuarine diversity of tintinnids (planktonic ciliates). J Plankton Res 23, 1009-1027.

Fenchel, T., Esteban, G. F. \& Finlay, B. J. (1997). Local versus global diversity of microorganisms: cryptic diversity of ciliated protozoa. Oikos 80, 220-225.

Foissner, W. (1997). Global soil ciliate (Protozoa, ciliophora) diversity: a probability-based approach using large sample collections from Africa, Australia and Antarctica. Biodivers Conserv 6, 1627-1638.

Foissner, W. (1998). An updated compilation of world soil ciliates (Protozoa, Ciliophora), with ecological notes, new records, and descriptions of new species. Eur J Protistol 34, 195-235.

Foissner, W. (1999). Protist diversity: estimates of the nearimponderable. Protist 150, 363-368.

Gold, K. \& Morales, E. A. (1975). Seasonal changes in lorica sizes and the species of Tintinnida in the New York Bight. J Protozool 22, 520-528.

Hedin, H. (1974). Tintinnids on the Swedish west coast. Zoon 2 , 127-137.

Hoffmann, D. C. \& Prescott, D. M. (1997). Phylogenetic relationships among hypotrichous ciliates determined with the macronuclear gene encoding the large, catalytic subunit of DNA polymerase alpha. $J \mathrm{Mol}$ Evol 45, 301-310.

Holzmann, M., Piller, W. \& Pawlowski, J. (1996). Sequence variations in the large-subunit ribosomal RNA gene of Ammonia (Foraminifera, Protozoa) and their evolutionary implications. J Mol Evol 43, 145-151.

Israel, R. L., Kosakovsky Pond, S. L., Muse, S. V. \& Katz, L. A. (2002). Evolution of duplicated alpha-tubulin genes in ciliates. Evolution 56, 1110-1122.
Kahl, A. (1930-1935). Urtiere oder Protozoa. I. Wimpertiere oder Ciliata (Infusoria) In Die Tierwelt Deutschlands. Edited by F. Dahl. Jena: Gustav Fischer.

Kusch, J., Welter, H., Stremmel, M. \& Schmidt, H. J. (2000). Genetic diversity in populations of a freshwater ciliate. Hydrobiologia 431, 185-192.

Laval-Peuto, M. (1977). Reconstruction d'une lorica de forme Coxliella par le trophonte nu de Favella ehrenbergii (Ciliata. Tintinnina). CR Acad Sci Paris 284, 547-550.

Laval-Peuto, M. (1981). Construction of the lorica in Ciliata Tintinnina. In vivo study of Favella ehrenbergii: variability of the phenotypes during the cycle, biology, statistics, biometry. Protistologica 17, 242-279.

Laval-Peuto, M. \& Brownlee, D. C. (1986). Identification and systematics of the Tintinnina (Ciliophora) - evaluation and suggestions for improvement. Ann Inst Oceanogr 62, 69-84.

Lee, J. J., Hutner, S. H. \& Bovee, E. C. (1985). An Illustrated Guide to the Protozoa. Lawrence, KS: Society of Protozoologists.

Lockhart, P. J., Larkum, A. W. D., Steel, M. A., Waddell, P. J. \& Penny, D. (1996). Evolution of chlorophyll and bacteriochlorophyll: the problem of invariant sites in sequence analysis. Proc Natl Acad Sci U S A 93, 1930-1934.

Lynn, D. H. \& Corliss, J. O. (1991). Ciliophora. In Microscopic Anatomy of Invertebrates, pp. 333-467. Edited by F. W. Harrison. New York: Wiley.

Maeda, M. (1986). An illustrated guide to the species of the families Halteriidae and Strobilidiidae (Oligotrichida, Ciliophora) free swimming protozoa common in the aquatic environment. Bull Ocean Res Inst 21, 1-67.

Marshall, S. M. (1969). Protozoa - Order Tintinnida. Cons Int Explor Mer Zooplankton Sheet 117-127, 1-81.

McManus, G. B. \& Fuhrman, J. A. (1986). Photosynthetic pigments in the ciliate Laboea strobila from Long Island Sound, USA. J Plankton Res 8, 317-327.

Medlin, L., Elwood, H. J., Stickel, S. \& Sogin, M. L. (1988). The characterization of enzymatically amplified eukaryotes $16 \mathrm{~S}$-like ribosomal RNA coding regions. Gene 71, 491-500.

Montagnes, D. J. S. \& Lynn, D. H. (1987). A quantitative protargol stain (QPS) for ciliates: method description and test of its quantitative nature. Mar Microb Food Webs 2, 83-93.

Montagnes, D. J. S. \& Lynn, D. H. (1991). Taxonomy of choreotrichs, the major marine ciliates, with emphasis on the aloricate forms. Mar Microb Food Webs 5, 59-74.

Norris, R. D. \& de Vargas, C. (2000). Evolution all at sea. Nature 405, 23-24.

Perez, M. T., Dolan, J. R., Vidussi, F. \& Fukai, E. (2000). Diel vertical distribution of planktonic ciliates within the surface layer of the NW Mediterranean (May 1995). Deep-Sea Res Part I Oceanogr Res Pap 47, 479-503.

Petz, W. \& Foissner, W. (1992). Morphology and morphogenesis of Strobilidium caudatum (Fromentel), Meseres corlissi N. Sp, Halteria grandinella (Muller), and Strombidium rehwaldi $\mathrm{N}-\mathrm{Sp}$, and a proposed phylogenetic system for oligotrich ciliates (Protozoa, Ciliophora). J Protozool 39, 159-176.

Pierce, R. W. \& Turner, J. T. (1993). Global biogeography of marine tintinnids. Mar Ecol Prog Ser 94, 11-26.

Posada, D. \& Crandall, K. (1998). modeltest: testing the model of DNA substitution. Bioinformatics 14, 817-818.

Riley, J. L. \& Katz, L. A. (2001). Widespread distribution of extensive genome fragmentation in ciliates. Mol Biol Evol 18, 1372-1377.

Saiki, R. K., Gelfand, D. H., Stoffel, S., Scharf, S. J., Higuchi, R., Horn, G. T., Mullis, K. B. \& Erlich, H. A. (1988). Primer-directed enzymatic amplification of DNA with a thermostable DNApolymerase. Science $\mathbf{2 3 9}$, 487-491.

Shin, M. K., Hwang, U. W., Kim, W., Wright, A. D. G., Krawczyk, C. \& Lynn, D. H. (2000). Phylogenetic position of the ciliates Phacodinium (Order Phacodiniida) and Protocruzia (Subclass Protocruziidia) and 
systematics of the spirotrich ciliates examined by small subunit ribosomal RNA gene sequences. Eur J Protistol 36, 293-302.

Small, E. B. \& Lynn, D. H. (1985). Phylum Ciliophora, Doflein 1901. In An Illustrated Guide to the Protozoa, pp. 393-575. Edited by J. J. Lee, S. H. Hutner \& E. C. Bovee. Lawrence, KS: Society of Protozoologists. Swofford, D. (1999). PAUP*. Phylogenetic Analysis Using Parsimony (*and Other Methods). Sunderland, MA: Sinauer.

Swofford, D. L., Olsen, G. J., Waddell, P. J. \& Hillis, D. M. (1996). Phylogenetic inference. In Molecular Systematics, pp. 407-514. Edited by D. M. Hillis, C. Moritz \& B. K. Mable. Sunderland, MA: Sinauer.

Tamura, K. \& Nei, M. (1993). Estimation of the number of nucleotide substitutions in the control region of mitochondrial DNA in humans and chimpanzees. Mol Biol Evol 10, 512-526.

Thompson, G. A., Alder, V. A., Boltovskoy, D. \& Brandini, F. (1999).
Abundance and biogeography of tintinnids (Ciliophora) and associated microzooplankton in the Southwestern Atlantic Ocean. J Plankton Res 21, 1265-1298.

Thompson, J. D., Higgins, D. G. \& Gibson, T. J. (1994). Clustal W: improving the sensitivity of progressive multiple sequence alignment through sequence weighting, position-specific gap penalties and weight matrix choice. Nucleic Acids Res 22, 4673-4680.

Tourancheau, A. B., Delgado, P., Perasso, R. \& Adoutte, A. (1992). A broad molecular phylogeny of ciliates: identification of major evolutionary trends and radiations within the phylum. Proc Natl Acad Sci U S A 89, 9764-9768.

Tourancheau, A. B., Villalobo, E., Tsao, N., Torres, A. \& Pearlman, R. E. (1998). Protein coding gene trees in ciliates: comparisons with rRNA-based phylogenies. Mol Phyl Evol 10, 299-309. 